\title{
Resolving ice cloud optical thickness biases between CALIOP and MODIS using infrared retrievals
}

\author{
Robert E. Holz ${ }^{1}$, Steven Platnick ${ }^{2}$, Kerry Meyer ${ }^{3}$, Mark Vaughan ${ }^{4}$, Andrew Heidinger ${ }^{5}$, Ping Yang ${ }^{6}$, Gala Wind ${ }^{7}$, \\ Steven Dutcher $^{1}$, Steven Ackerman ${ }^{1}$, Nandana Amarasinghe ${ }^{7}$, Fredrick Nagle ${ }^{1}$, and Chenxi Wang ${ }^{8}$ \\ ${ }^{1}$ University of Wisconsin-Madison Space Science and Engineering Cent, Madison, WI, USA \\ ${ }^{2}$ NASA Goddard, Greenbelt, MD, USA \\ ${ }^{3}$ GESTAR/USRA, Greenbelt, MD, USA \\ ${ }^{4}$ NASA Langley, Langley, VA, USA \\ ${ }^{5}$ NOAA, Madison, WI, USA \\ ${ }^{6}$ Texas A\&M University, College Station, TX, USA \\ ${ }^{7}$ SSAI, Greenbelt, MD, USA \\ ${ }^{8}$ University of Maryland, College Park, MD, USA \\ Correspondence to: Robert E. Holz (reholz@ssec.wisc.edu)
}

Received: 1 September 2015 - Published in Atmos. Chem. Phys. Discuss.: 29 October 2015

Revised: 9 February 2016 - Accepted: 29 March 2016 - Published: 25 April 2016

\begin{abstract}
Despite its importance as one of the key radiative properties that determines the impact of upper tropospheric clouds on the radiation balance, ice cloud optical thickness (IOT) has proven to be one of the more challenging properties to retrieve from space-based remote sensing measurements. In particular, optically thin upper tropospheric ice clouds (cirrus) have been especially challenging due to their tenuous nature, extensive spatial scales, and complex particle shapes and light-scattering characteristics. The lack of independent validation motivates the investigation presented in this paper, wherein systematic biases between MODIS Collection 5 (C5) and CALIOP Version 3 (V3) unconstrained retrievals of tenuous IOT $(<3)$ are examined using a month of collocated A-Train observations. An initial comparison revealed a factor of 2 bias between the MODIS and CALIOP IOT retrievals. This bias is investigated using an infrared (IR) radiative closure approach that compares both products with MODIS IR cirrus retrievals developed for this assessment. The analysis finds that both the MODIS C5 and the unconstrained CALIOP V3 retrievals are biased (high and low, respectively) relative to the IR IOT retrievals. Based on this finding, the MODIS and CALIOP algorithms are investigated with the goal of explaining and minimizing the biases relative to the IR. For MODIS we find that the assumed ice single-scattering properties used for the C5 retrievals are not
\end{abstract}

consistent with the mean IR COT distribution. The C5 ice scattering database results in the asymmetry parameter $(g)$ varying as a function of effective radius with mean values that are too large. The MODIS retrievals have been brought into agreement with the IR by adopting a new ice scattering model for Collection 6 (C6) consisting of a modified gamma distribution comprised of a single habit (severely roughened aggregated columns); the C6 ice cloud optical property models have a constant $g \approx 0.75$ in the mid-visible spectrum, 5 $15 \%$ smaller than C5. For CALIOP, the assumed lidar ratio for unconstrained retrievals is fixed at $25 \mathrm{sr}$ for the V3 data products. This value is found to be inconsistent with the constrained (predominantly nighttime) CALIOP retrievals. An experimental data set was produced using a modified lidar ratio of $32 \mathrm{sr}$ for the unconstrained retrievals (an increase of $28 \%$ ), selected to provide consistency with the constrained V3 results. These modifications greatly improve the agreement with the IR and provide consistency between the MODIS and CALIOP products. Based on these results the recently released MODIS C6 optical products use the singlehabit distribution given above, while the upcoming CALIOP V4 unconstrained algorithm will use higher lidar ratios for unconstrained retrievals. 


\section{Introduction}

While clouds represent one of the largest modulators of Earth's radiation, with their impact dependent on a variety of cloud physical and radiative properties, they remain one of the more difficult components to represent in global climate models (Jiang et al., 2012). Passive satellite observational data sets such as those from MODIS (Moderate Resolution Imaging Spectroradiometer), AVHRR (Advanced Very High Resolution Radiometer), HIRS (High-spectral Infrared Sounder), and ISCCP (International Satellite Cloud Climatology Project) provide long-term, global cloud observations (Wylie et al., 2005; Heidinger et al., 2013; King et al., 2013, 2003; Rossow, 1991; Rossow and Schiffer, 1999). However, assessing the uncertainties in the cloud radiative properties retrieved by these sensors has proved to be a complex and difficult task. Until recently, validation of these retrievals was limited to ground and aircraft intercomparisons. But with the successful launch of CALIPSO (Cloud-Aerosol Lidar and Infrared Pathfinder Satellite Observations) and CloudSat in April 2006 as part of the NASA-led Afternoon Constellation (A-Train) (Stephens et al., 2002; Winker et al., 2010), researchers now have access to a near-continuous global record of vertically resolved observations of cloud and aerosol properties with nearly coincident observations from MODIS Aqua.

Since launch, the CALIPSO lidar (the Cloud Aerosol Lidar with Orthogonal Polarization, or CALIOP) has proven to be a valuable tool for developing and evaluating passive cloud retrievals (Ackerman et al., 2008; Delanoë and Hogan, 2010; Holz et al., 2008; Jin and Nasiri, 2013; Kahn et al., 2014). CALIOP can directly measure cloud-top height with sensitivities that are significantly greater than the passive retrievals, while the CALIOP depolarization and attenuated backscatter measurements provide vertically resolved cloud phase discrimination (Hu et al., 2009) for cloud layers up to a cumulative optical depth of about 3 .

Ice optical thickness (IOT) has also proved to be one of the more difficult properties to retrieve from space-based passive sensor measurements and challenging to validate. In particular, it is difficult to infer the microphysical and radiative properties of optically thin upper tropospheric ice clouds (cirrus) from observations made by passive spaceborne instruments due to their tenuous nature, extensive spatial scales, complex particle shapes, and a wide range of particle sizes. Active sensors such as CALIOP have the advantage that they directly measure the vertical structure of clouds and aerosols however similar to the passive retrievals, assumptions regarding the ice scattering properties (i.e., lidar ratio and multiple scattering) are necessary to invert the lidar signal and retrieve the ice cloud extinction. This lack of constraints in both the MODIS and CALIOP ice cloud retrievals results in considerable uncertainty and potential bias in the IOT, which is the focus of the paper. The paper begins by presenting an intercomparison between the MODIS C5 and CALIOP

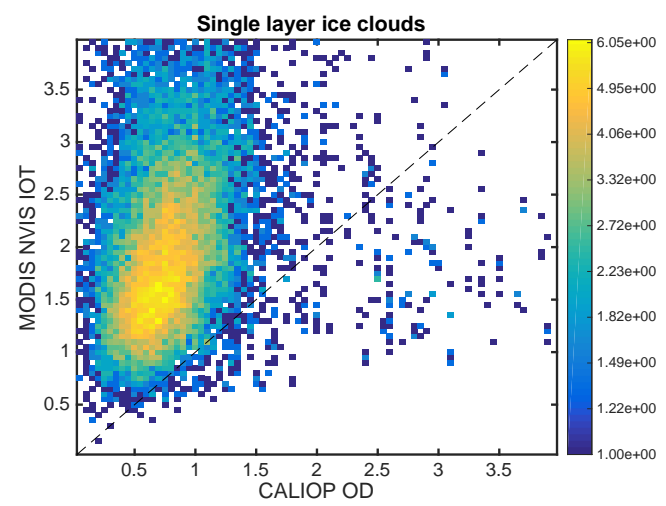

Figure 1. A two-dimensional histogram comparing MODIS C5 and CALIOP V3 single-layer ice cloud daytime optical thickness retrievals for January 2010 (ocean surfaces, $\pm 60^{\circ}$ latitude). Note that the color scale is logarithmic.

V3 IOT retrievals for optical tenuous cirrus (IOT <3.0). A factor of 2 bias is found between MODIS and CALIOP unconstrained retrievals (presented in Fig. 1) and described in Sect. 4, raising a major question regarding the utility of these data records to study ice cloud radiative processes. We next investigate the bias using an infrared (IR) radiative closure experiment using collocated the MODIS $11 \mu \mathrm{m}$ observations. Based on these results, modifications to the MODIS optical property retrievals with a focus on the ice scattering models are investigated. For CALIOP, experimentation with the value of the assumed lidar ratio used in the unconstrained retrieval is evaluated. The result from this study provides the basis for the change in the ice scattering models used by the recently released MODIS C6 ice cloud products and for CALIOP the results provide one of the key studies motivating the changes to the CALIOP ice cloud extinction retrievals in the upcoming V4 product.

\section{MODIS and CALIOP retrieval background}

Both MODIS and CALIOP IOT retrievals require a priori information concerning the ice particle scattering properties that relate the measured reflectance (MODIS) or attenuated backscatter (CALIOP) to the cloud's IOT and potentially the effective particle size. MODIS ice cloud forward radiative calculations in the visible-near-infrared (VNIR) depend directly on the ice particle phase function assumption, and to a first order on the associated asymmetry parameter $(g)$. For CALIOP, an assumed extinction-to-backscatter ratio is required for the unconstrained retrievals where the algorithm is unable to make reliable estimates of cirrus IOT by measuring the attenuated backscatter coefficients in some clear-air region immediately above and below cloud base (Young and Vaughan, 2009). Because solar background signals greatly reduce the signal-to-noise ratio (SNR) of the CALIOP daytime measurements, the vast majority of CALIOP daytime IOT estimates are derived from unconstrained retrievals. 
Uncertainties in the ice scattering property assumptions of MODIS and/or CALIOP could account for the biases found in Fig. 1. As will be discussed, an infrared (IR) cirrus IOT retrieval is relatively insensitive to ice particle size and scattering details compared to MODIS and CALIOP VNIR measurements and thus provides an independent means to assess thin to moderately optically thick ice cloud retrievals (IOT $\sim 0-3$ ). In addition, an IR retrieval provides radiative closure with solar reflectance based on MODIS IOT retrievals in the sense that consistency in the two retrieved IOTs also implies forward model consistency with the respective top-of-atmosphere (TOA) VNIR and IR observations.

Using the NASA-funded SSEC Atmosphere Product Evaluation and Test Element (PEATE), now re-named the SuomiNPP Atmosphere Science Investigator Processing System (SIPS), the sensitivity of MODIS retrievals to ice singlescattering properties are investigated by repeated analyses of collocated January 2010 CALIOP and MODIS observations using a variety of ice crystal habits (Yang et al., 2012) and size distributions. Based on comparisons against IR retrievals, the MODIS MYD06 Collection 6 (C6) ice cloud optical property algorithm uses a single habit - severely roughened aggregated columns (Yang et al., 2012) - instead of the size-dependent multi-habit model (Baum et al., 2005) used for C5. The MYD06 C6 results compare well with a new CALIOP version that uses a modified (larger) extinction-tobackscattering ratio for unconstrained IOT retrievals.

The manuscript is organized as follows. Section 2 presents a detailed description of the algorithms and data sets used in the analysis of the ice cloud optical depths with a focus on the IR retrievals. Section 3 introduces the global intercomparison between the MODIS Collection 5 and CALIPSO V3 ice cloud optical depths, with Sect. 4 presenting the comparison with the collocated IR retrievals (ocean only). Section 5 discusses the impact of the ice model selection (MODIS) and the assumed lidar ratio and multiple-scattering correction (CALIOP) on the ice cloud optical depth and then presents an intercomparison of the MODIS and CALIOP retrievals processed using a modified single-scatter lookup table (severely roughened aggregated columns) and a modified of unconstrained lidar ratio of 31 (instead of 25 for V3). Section 6 summarizes the results and with a focus on the rational for the selection of a single habit for the new single-scattering properties for the MODIS C6 ice cloud retrievals.

\section{Ice cloud optical thickness retrieval data sets}

An overview of the relevant retrieval methodologies is presented here with a focus on the forward cloudy radiative transfer modeling assumptions and IR IOT retrievals developed specifically for this study.

\subsection{IR retrievals and radiative closure}

The MODIS channel suite includes a range of IR channels extending well into the $\mathrm{CO}_{2}$ absorption region $(13-15 \mu \mathrm{m})$. The calibration of the IR channels has been extensively validated and proven to have high accuracy, with uncertainties less than $0.5 \mathrm{~K}$ across a broad temperature range (Tobin et al., 2006). For ice clouds, the IR radiative transfer is dominated by absorption, and thus is less complex than for the VNIR retrieval. In this section we discuss the IR radiative transfer methodology that is used both to retrieve the IR IOT as well as evaluate the MODIS and CALIOP retrievals.

The goal of radiative closure study is to relate the differences in the CALIOP and MODIS retrieved IOT to the measured TOA channel radiance or brightness temperature (BT) in the MODIS $11 \mu \mathrm{m}$ channel. To calculate the TOA cloudy radiances requires an accurate radiative transfer model, knowledge of the cloud boundaries, and well-characterized surface temperature/emissivity and atmospheric thermodynamic profiles. LBLDIS (Turner et al., 2003), a cloudy radiative transfer model, is used for this analysis. The model elegantly combines the clear-sky Line-By-Line Radiative Transfer Model (LBLRTM) (Clough and Moncet, 1992) with the Discrete Ordinates Radiative Transfer (DISORT) (Stamnes et al., 1988), a proven and accurate cloudy radiative transfer model. The inputs required for LBLRTM are surface temperature and emissivity, vertically resolved temperature and water vapor profiles, and information regarding trace gas concentrations such as $\mathrm{CO}_{2}$ and $\mathrm{O}_{3}$. For this analysis the surface temperature and thermodynamic profiles are extracted from the NOAA Global Data Assimilation System (GDAS) files that provide profiles at $1^{\circ}$ spatial resolution every $6 \mathrm{~h}$. For each MODIS and CALIOP field of view (FOV), the closest (in both time and space) GDAS profile is selected. A fixed $\mathrm{CO}_{2}$ concentration of $380 \mathrm{ppm}$ and a climatological $\mathrm{O}_{3}$ profile is used. Given these inputs, LBLRTM is run on the selected FOV filtered using the collocated CALIOP V3 $5 \mathrm{~km}$ cloud layer products (described in Sect. 3). The results of the clear-sky validation are discussed in Sect. 4.

The cloud microphysics and thermodynamics are defined with a vertical resolution of $500 \mathrm{~m}$ within the cloud boundaries defined by the CALIOP layer product. Only FOV where the CALIOP is not attenuated at the surface are used greatly reducing uncertainties in the cloud base determination. For example a cloud with a geometrical thickness of $1.5 \mathrm{~km}$ is divided into three layers, with each layer defined by an optical thickness, effective radius, and ice scattering model. For example, for a cloud with a total optical thickness of 1.5, each layer will have an optical thickness of 0.5 . Using this methodology the vertical temperature profile is accounted for in the radiative transfer. For daytime IR forward model calculations, the effective radius from the MODIS optical property retrieval is used for all cloud layers. For nighttime CALIOP comparisons, a fixed effective radius of $40 \mu \mathrm{m}$ is used in the IR calculations. It is important to note that at $11 \mu \mathrm{m}$ the IOT 
retrieval is relatively insensitive to the assumed effective radius.

The last remaining variable needed to calculate the TOA IR radiance is IOT. LBLDIS is run independently using either the MODIS or CALIOP retrieved IOT, resulting in highspectral-resolution TOA radiances with the only differences being the assumed IOT (i.e., MODIS or CALIOP). The spectrally resolved radiances are then integrated over the MODIS Aqua $11 \mu \mathrm{m}$ channel (band 31) spectral response function, resulting in a simulated TOA radiance that can be directly compared to the measured MODIS $11 \mu \mathrm{m}$ observations.

In addition to LBLDIS spectral calculations, TOA longwave fluxes are calculated using the Rapid Radiative Transfer Model (RRTM) (Mlawer et al., 1997), which is also based on DISORT and LBLRTM and utilizes a correlated- $k$ method for gas absorption along with broadband ice cloud parameterizations from (Fu et al., 2000). Identical inputs are used for RRTM and the LBLDIS TOA calculations with the only variable being IOT. The TOA fluxes are subsequently used to quantify the impact of the IOT biases on the global characterization of ice cloud radiative forcing.

IR observations provide the independent reference to understand differences between MODIS and CALIOP IOT retrievals. While radiance closure provides valuable information regarding TOA radiances and fluxes, it does not provide a direct assessment of the individual CALIOP and MODIS IOT biases. To convert observed IR TOA radiance to IOT, two different retrieval approaches were used. First, we developed an IR window IOT retrieval that uses the collocated MODIS and CALIOP observations. This "reference" retrieval uses cloud boundary information from CALIOP coupled with the LBLDIS forward model and then retrieves the IR IOT using the MODIS $11 \mu \mathrm{m}$ window channel observations that are coincident and collocated with CALIOP. A second method uses the spectral emissivity retrieved from the MODIS $\mathrm{CO}_{2}$ emissive cloud-top pressure retrieval that is then related to the IOT and effective radius using a precomputed lookup table (Heidinger et al., 2015). This method has the advantage of being computationally very efficient, not requiring the CALIOP cloud boundaries, and providing IOT for the entire MODIS swath. Both IR retrieval methods are discussed in more detail in the following subsections.

\subsubsection{Combined MODIS IR window and CALIOP retrievals}

A single channel IR window IOT retrieval was developed for this study using combined CALIOP and MODIS observations and the LBLDIS forward radiative transfer modeling discussed in the previous section. The method constrains the cloud boundaries using the collocated CALIOP $5 \mathrm{~km}$ layer products and uses surface and atmospheric temperatures information from GDAS. TOA radiances are simulated using LBLDIS with IOT retrieved by minimizing the measured MODIS channel $31(11 \mu \mathrm{m})$ and calculated BT differences.
The retrieval assumes the cloud extinction is evenly distributed in the vertical throughout the cloud. This simplification has the potential to bias the retrieval for FOV where the IOT is distributed non-uniformly in the vertical (Maestri and Holz, 2009). The cloud geometric thickness is thus limited to no greater than $4 \mathrm{~km}$ to reduce IOT biases that can be introduced by non-homogeneous layers.

\subsubsection{MODIS IR spectral emissivity retrievals}

The MODIS $\mathrm{C} 6 \mathrm{CO}_{2}$ slicing algorithm provides retrieved spectral emissivity for the $8.5,11$, and $12 \mu \mathrm{m}$ channels (channels $29,31,32)$ that have sensitivity to both the IOT and effective radius. As described in (Parol et al., 1991), $\beta$ ratios can be approximated based on these emissivities and are related to the asymmetry parameter $(g)$, single-scattering albedo $\left(\omega_{\mathrm{o}}\right)$, and extinction efficiency $\left(Q_{\mathrm{e}}\right)$ as follows:

$\beta_{\lambda_{1} \lambda_{2}}=\mid Q_{\mathrm{e}, \lambda_{1}}\left(1-\omega_{0, \lambda_{1}} g_{\lambda_{1}}\right) / Q_{\mathrm{e}, \lambda_{2}}\left(1-\omega_{\mathrm{o}, \lambda_{2}} g_{\lambda_{2}}\right)$.

Thus, $\beta$ is the ratio of the scaled absorption extinction in two spectral channels $\left(\lambda_{1}\right.$ and $\left.\lambda_{2}\right)$. The effective radius is first retrieved by matching simulated ice single-scattering calculations of $g(r), \omega_{\mathrm{o}}(r)$, and $Q_{\mathrm{e}}(r)$, each integrated over the appropriate MODIS spectral response functions, to the retrieved MODIS $\beta$ ratios which are calculated for both the $8.5-11$ and $11-12 \mu \mathrm{m}$ pairs. For this analysis the scattering properties of severely roughened aggregated columns (Yang et al., 2012) are used to be consistent with the MODIS C6 cloud optical property retrievals.

Using the effective radius to define $g(r), \omega_{\mathrm{o}}(r)$, and $Q_{\mathrm{e}}(r)$, the extinction optical thickness is then retrieved by relating the $11 \mu \mathrm{m}$ emissivity to the extinction optical thickness in the form (Van de Hulst 1974):

$\tau_{\text {vis }}=\frac{2}{Q_{\mathrm{e}}}\left(\frac{\tau_{\mathrm{abs}}}{\left(1-\omega_{\mathrm{o}} g\right)}\right)$,

where $\tau_{\text {abs }}$ is the IR absorption optical thickness and $\tau_{\text {vis }}$ is the extinction optical thickness at $532 \mathrm{~nm}$. This derivation assumes that the ratio between the absorption and extinction optical thickness is a factor of 2 in the IR. Based on ice cloud single-scattering calculations (Yang et al., 2012) and assuming that the majority of ice clouds have an effective radius greater than $10 \mu \mathrm{m}$, this assumption is expected to have introduced no more than $10 \%$ uncertainty. Heidinger et al. (2015) provides a more detailed discussion of the retrieval methodology. This approach can be applied without the need for the CALIOP cloud boundaries, and provides full-swath IR IOT retrievals. We leverage this capability to investigate the MODIS IOT retrieval biases as a function of view angle.

\subsection{CALIOP ice cloud optical thickness retrievals}

CALIOP is a two-wavelength elastic backscatter lidar that measures attenuated backscatter components polarized parallel and perpendicular to the transmitted laser light at $532 \mathrm{~nm}$ 
and total attenuated backscatter at $1064 \mathrm{~nm}$ (Hunt et al., 2009). Once the received signals have been backgroundsubtracted and calibrated (Powell et al., 2009), a tightly integrated suite of retrieval algorithms is used to detect layer boundaries (Vaughan et al., 2009) and classify layers as either clouds or aerosols (Liu et al., 2009). Layers classified as clouds are further classified according to thermodynamic phase as either ice clouds or water clouds (Hu et al., 2009). Layer optical thickness (including IOT) is then retrieved using one of two techniques: constrained or unconstrained retrievals (Young and Vaughan, 2009). Constrained retrievals are applied whenever the effective two-way transmittance of a layer,

$T_{\text {eff }}^{2}=\exp (-2 \eta \tau)=\exp \left(-2 \eta \int_{\text {layer top }}^{\text {layer base }} \sigma_{\mathrm{c}}(r) \mathrm{d} r\right)$,

can be directly and reliably measured. In this expression $\tau$ is the layer optical depth (IOT for ice clouds), $\sigma_{\mathrm{c}}(r)$ is the range-resolved cloud extinction coefficient, and $\eta$ is a multiple-scattering correction factor whose value depends on the lidar sensing geometry and the scattering characteristics of the particulates being measured. While $T_{\text {eff }}^{2}$ estimates can be obtained from measurements of clear air, opaque water clouds, and ocean surfaces (see Josset et al., 2012; Yongxiang et al., 2007; and Young, 1995, respectively), the CALIOP V3 algorithm only implements the clear-air technique, in which $T_{\text {eff }}^{2}$ can be obtained directly from the ratio of the mean attenuated scattering ratios calculated in regions of clear air located immediately above cloud top and below cloud base (Vaughan et al., 2005). Retrieving IOT from measurements of $T_{\text {eff }}^{2}$ requires knowledge of the appropriate multiple-scattering factor (Winker, 2003). For CALIOP measurements of cirrus clouds, Josset et al. (2012) determined the mean multiple-scattering factor to be $0.61 \pm 0.15$. In the CALIOP V3 algorithm, $\eta$ is fixed at 0.6 for all cirrus clouds. More recent results suggest that the multiple-scattering factor is dependent on cloud temperature (Garnier et al., 2015b), which is being considering for the upcoming version 4 products.

Constrained retrievals are the preferred method for retrieving IOT from CALIOP measurements. However, because solar background light significantly degrades the CALIOP SNR during daylight operations, V3 constrained retrievals occur almost exclusively during nighttime observations, thus severely limiting direct comparisons with MODIS IOT retrievals derived from VNIR solar reflectance. For the vast majority of daytime observations, CALIOP IOT retrievals use an unconstrained technique that requires a priori knowledge of the cirrus extinction-to-backscatter ratio (i.e., lidar ratio),

$S_{\mathrm{c}}=\frac{\sigma_{\mathrm{c}}(r)}{\beta_{\mathrm{c}}(r)}$, where $\sigma_{\mathrm{c}}(r)$ and $\beta_{\mathrm{c}}(r)$ are, respectively, the cloud extinction and backscatter coefficients. IOT is then obtained by solving the lidar equation using specified values of $\eta$ and $S_{\mathrm{c}}$ (Young and Vaughan, 2009). Note that while the cloud extinction and backscatter coefficients are explicitly range-dependent, their ratio is assumed to be range-invariant. Although $S_{\mathrm{c}}$ for ice clouds most likely varies depending on crystal habit and size distribution, the CALIOP V3 unconstrained retrievals use a globally constant default value of $S_{\mathrm{c}}=25 \mathrm{sr}$. Based on ground-based lidar observations there can be significant variability in the lidar ratio. The constant value is considered one of the primary sources of uncertainty in the V 3 ice cloud extinction retrievals. This value was determined prior to launch from the best information available from numerous groundbased and airborne data sets (e.g., Holz, 2002; Sassen and Comstock, 2001; Yorks et al., 2011).

Errors in lidar ratio selection for unconstrained retrievals generate corresponding errors in the resultant estimates of IOT. In particular, an underestimate of $S_{\mathrm{c}}$ will result in CALIOP underestimating IOT. The selection of the default CALIOP lidar ratio is thus one of the potential major sources of bias in the CALIOP unconstrained retrievals that can be investigated using IR observations from either MODIS or the CALIPSO IIR (Imaging Infrared Radiometer) instrument (Garnier et al., 2015a).

\subsection{MODIS ice cloud optical thickness retrievals}

The MODIS imager provides measurements in 36 spectral channels, covering the visible-near-infrared (VNIR), shortwave infrared (SWIR), midwave infrared (MWIR), and thermal IR portions of the spectrum. Spatial resolution is $250 \mathrm{~m}$ in two VNIR channels, $500 \mathrm{~m}$ in the five VIS/SWIR channels, and $1 \mathrm{~km}$ in the remaining channels.

The MODIS cloud optical/microphysical property algorithm is used to generate a single cloud product designated by the NASA Earth Science Data Type (ESDT) names MOD06 and MYD06 for Terra and Aqua MODIS, respectively (hereafter referred to as MYD06 since the algorithms are essentially identical and this study is focused on MODIS Aqua observations). For daytime measurements, the $1 \mathrm{~km}$ cloud retrieval algorithm uses multiple spectral channels (primarily six VNIR, SWIR, and MWIR channels, as well as several thermal channels) to simultaneously retrieve cloud optical thickness, effective radius (and derived water path) and thermodynamic phase for liquid- and ice-phase clouds. In addition to the $1 \mathrm{~km}$ MODIS Level-1B calibrated radiance product, the algorithm requires the following input: MODIS cloud mask (MYD35) including $250 \mathrm{~m}$ mask information (Ackerman et al., 1998), the cloud-top pressure portion of MYD06 (Ackerman et al., 2008; Holz et al., 2008), and a variety of ancillary data sets. Heritage algorithm work is discussed in King et al. (2003), Nakajima and King (1990), Platnick and Twomey (1994), and Platnick et al. (2001). 
C5 algorithm-related publications include ice radiative models (Ackerman et al., 2008; Baum et al., 2005; Yang et al., 2007), multilayer detection (Wind et al., 2010), clearsky restoral filtering (Pincus et al., 2012; Zhang and Platnick, 2011), pixel-level uncertainties, and L3 global gridded statistics (King et al., 2013). An online list of the recent C6 algorithm updates is available from the MODIS Atmosphere Team website (Platnick, 2014). The most relevant update for the current discussion is the adoption of new ice cloud radiative models having an overall smaller asymmetry parameter, as will be discussed in Sect. 5.1. Note that, for consistency with the spherical droplet definition, as well as for use in deriving ice water path, the effective radius of a non-spherical ice particle is defined as 3/4 times the ratio of the average volume of the size distribution to the average cross-sectional area (Yang et al., 2007).

\subsection{Collocation and the merged data set}

In this section we present the methods used to collocate and merge the CALIOP and MODIS observations providing the foundation for the intercomparisons and analysis presented in the results of Sect. 4.

The analysis is based on 1 month (January 2010) of physically collocated CALIOP and MODIS observations. MODIS is an imaging radiometer, while CALIOP is a near-nadir viewing lidar. Because each instrument has a unique viewing geometry with different spatial resolutions, accurate intercomparisons require collocating the observation FOVs. This analysis uses tools that provide computationally efficient and accurate collocation (Nagle and Holz, 2009). The methodology defines master and follower instruments, with the master typically being the larger FOV and the follower FOV collocated within the master footprint. In this investigation MODIS is defined as the master with CALIOP the follower. The MODIS spatial resolution can be approximated as a rectangular box with a $1 \mathrm{~km} \times 2 \mathrm{~km}$ resolution at nadir. The CALIOP IOT retrieval can be performed over horizontal averaging distances ranging from 5 to $80 \mathrm{~km}$, depending on the magnitude of the cloud signal relative to the background noise (Yongxiang et al., 2007). The CALIOP surface footprint is therefore approximated as an $80 \mathrm{~m}$ wide swath with the along-track length depending on the amount of spatial averaging. The majority of observations used in this analysis are the $5 \mathrm{~km}$ averaged IOT. A more detailed description of the CALIOP and MODIS collocation is presented in Holz et al. (2008).

Leveraging the UW Atmospheric Science Investigator-led Processing System processing capabilities, a month of collocated MODIS and CALIOP collocated observations were processed using the CALIOP and MODIS IOT retrievals with the only difference being incremental changes to the ice cloud parameterizations used in the retrieval algorithms. This approach isolates the impact of the parameterization changes and/or algorithm modifications and provides a direct assessment of the changes in IOT.

\section{CALIOP V3 and MODIS C5 cirrus optical thickness intercomparisons}

Figure 1 presents the MODIS C5 IOT retrievals compared with CALIOP V3 IOT for 1 month (January 2010) of non-polar $\left( \pm 60^{\circ}\right.$ latitude $)$ daytime ocean observations. The CALIOP $5 \mathrm{~km}$ layer products are used to select only singlelayer ice clouds where both the CALIOP phase retrieval $\mathrm{CHu}$ et al., 2009) and the MODIS optical property phase retrieval identify ice clouds. The CALIOP phase detection is sensitive to scattering from oriented ice (specular reflection), and such cases are excluded from the data set. Because the CALIOP layer detection algorithm employs a nested, multiresolution spatial averaging scheme (Vaughan et al., 2009), the CALIOP $5 \mathrm{~km}$ layer products can report distinct layers in cases where the base of the upper layer is separated from the top of the lower layer by as little as a single range bin $(60 \mathrm{~m})$. For a passive retrieval such as from MODIS, a $60 \mathrm{~m}$ vertical separation will have little impact on the retrieval results assuming both layers are ice. To improve the comparison yield and provide a more representative distribution of single-layer ice clouds for intercomparing the passive observations, CALIOP $5 \mathrm{~km}$ ice cloud layers with a vertical separation of $3 \mathrm{~km}$ or less are merged to form single, vertically contiguous layers. The CALIOP extinction profile is then integrated for each profile using the redefined layer boundaries, thus providing an aggregated IOT. Ice clouds with total geometrical thickness greater than $4 \mathrm{~km}$ using this single-layer definition are excluded from the comparison.

The MODIS IOT retrievals are filtered using the C5 MODIS Quality Assurance (QA) parameters and a horizontal heterogeneity threshold. MODIS IOT retrievals (i.e., with the QA usefulness flag set to 1 and the QA confidence flag set to 3) are used in the comparison. This filtering provides all ice cloud retrieval where both the IOT and effective radius successfully converged within the lookup table. Unlike liquid water clouds, QA values of 2 and 1 are not used for C5 retrievals. Using this filtering provides the highest quality MODIS retrievals and removes all cloud edges from the comparison. To reduce uncertainties resulting from spatial sampling differences between MODIS and CALIOP, the standard deviation of a $5 \times 5$ pixel box centered over the collocated pixel is computed. Only collocated pixels where the MODIS IOT standard deviation is less than 0.5 are used; we find, however, that the comparison results are relatively insensitive to this threshold.

Figure 1 reveals a systematic bias between the MODIS C5 and CALIOP IOTs, with MODIS approximately a factor of 2 larger than the CALIOP unconstrained retrievals. An independent methodology is needed to assess this difference since both retrievals depend on ice scattering prop- 

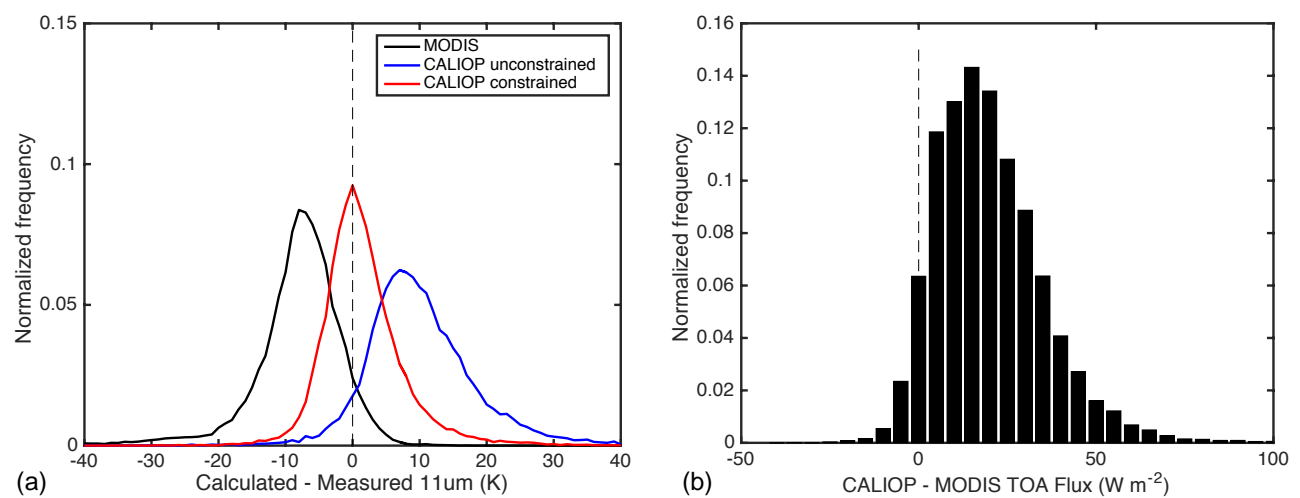

Figure 2. This figure presents the radiative closure results (a) for 1 month (January 2010) of collocated single-layer ice cloud observations using LBLRTM and DISORT to calculate the TOA $11 \mu \mathrm{m}$ radiance that are compared to MODIS channel 31 observations. The only difference in the calculations is the IOT retrieval method. The differences in TOA fluxes resulting from using the MODIS or CALIOP daytime IOT retrievals in the calculation are presented in the right histogram (b).

erty assumptions. As discussed in Sect. 2, the IR observations provide sensitivity to the IOT given well-constrained cloud boundaries with uncertainties that are independent of the CALIOP and MODIS VNIR retrievals. Spectrally resolved TOA radiances are calculated for the three different retrieval methods - MODIS, CALIOP unconstrained (daytime measurements), and CALIOP constrained (nighttime measurements) - using LBLRTM and LBLDIS. All three calculations use identical cloud boundaries defined by the merged CALIOP $5 \mathrm{~km}$ layer heights and the same thermodynamic profiles and ocean surface temperatures (GDAS), with the only difference being the IOT used in the calculation. The spectrally resolved TOA radiances are then integrated over the MODIS channel $31(11 \mu \mathrm{m})$ spectral response function. To investigate the accuracy of the combined GDAS and TOA clear-sky LBLRTM calculations, simulated TOA $11 \mu \mathrm{m}$ BT for clear-sky FOVs identified using both the MODIS and CALIOP cloud masks were compared to the measured MODIS $11 \mu \mathrm{m}$ channel BTs. The mean bias between the simulated and observed BT is less than $0.2 \mathrm{~K}$, which is within the expected calibration uncertainty of MODIS (Tobin et al., 2006).

Figure 2a presents the MODIS C5 and CALIOP V3 BT closure results. The figure reveals a sobering finding, which is that neither the MODIS C5 nor the CALIOP V3 unconstrained IOT retrievals provide radiative closure in the window IR. Furthermore, the respective retrievals are biased in opposite directions. For MODIS C5, the calculated TOA BT is colder than the measured BT with a mean bias of $-8.3 \mathrm{~K}$, implying the MODIS IOT is on average biased high. In contrast, the TOA BT calculated using the CALIOP V3 unconstrained IOT has a mean bias of $+10.2 \mathrm{~K}$, suggesting the CALIOP retrieval is biased low. The CALIOP V3 constrained retrievals, which do not require an assumed lidar ratio but only an estimate of the multiple-scattering correc- tion, demonstrate much better agreement with a mean bias of $+1.4 \mathrm{~K}$.

To put the biases into a radiative context, the cloudy IR TOA fluxes are computed for each collocation using RRTM. The calculations use the CALIOP cloud boundaries, the surface and atmospheric profiles from GDAS, and the MODIS retrieved effective radius. For each collocation, RRTM calculations are computed, with the only difference being the IOT used (MODIS or CALIOP) with the results presented in Fig. 2b. The mean TOA flux difference between MODIS and CALIOP unconstrained retrievals is $+20 \mathrm{~W} \mathrm{~m}^{-2}$ with a standard deviation of $15 \mathrm{~W} \mathrm{~m}^{-2}$. For the tenuous ice clouds being investigated, the sensitivity of the TOA flux to IOT is primarily driven by the thermal contrast between the surface and the mean emitting temperature of the cloud (Corti and Peter, 2009). The very large differences in the wings of the distribution in Fig. 1b occur primarily near the tropics, where the thermal contrast is greatest between the cloud and the surface. For this region TOA differences as large as $40 \mathrm{~W} \mathrm{~m}^{-2}$ are found in Fig. 2b.

\section{IR retrievals as a reference optical thickness}

Because the sensitivity of IR IOT retrievals to ice crystal habit selection is minimal, these retrievals provide an independent means to evaluate the CALIOP and MODIS solar reflectance retrievals. As discussed in Sect. 2, the main sources of uncertainty in the IR IOT originate from characterizing the surface temperature and having an accurate determination of the cloud emitting temperature. To reduce the surface temperature uncertainty, the results of this section are restricted to non-polar $\left( \pm 60^{\circ}\right)$ ocean-only cases.

The comparisons with IR window IOT retrievals shown in Fig. 3 reveal biases in both the MODIS (a) and daytime CALIOP unconstrained (b) retrievals (high and low, respectively) that are consistent with the radiative closure results 

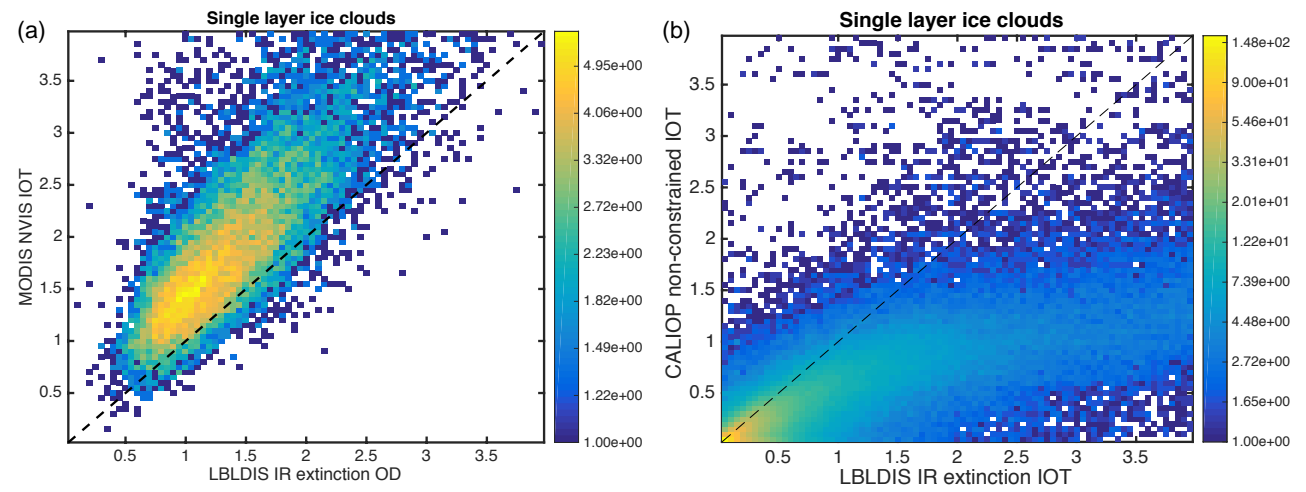

Figure 3. Two-dimensional histogram comparing the MODIS C5 (a) and CALIOP V3 (b) retrievals to the reference IR IOT retrieval.

presented in Fig. 2. The magnitude of the bias relative to the IR is approximately $+40 \%$ for MODIS. For CALIOP there is a nonlinear dependence between the IOT and the negative bias relative to the IR, with the bias increasing substantially for IR IOTs greater than unity; the CALIOP results are discussed further in Sect. 5.2.

A limitation of the IR window IOT data set is that only a small subset of the MODIS across-track swath can be assessed due to the very close coordination between the MODIS and CALIOP orbits. To investigate MODIS IOT scan angle dependencies we use the MODIS spectral IR IOT retrieval described in Sect. 2.1.2. Figure 4a shows the MODIS C5 liquid- (warm colors) and ice-phase (cool colors) cloud optical thickness for an example MODIS data granule (11 January 2010, 06:25 UTC). Figure 4b presents the histogram of the ratio between the MODIS IOT and the fullswath IR IOT (described in Sect. 2.1.2) separated by viewing angle ranges as indicated by the colored lines overlaid on the IOT image. A ratio of unity would suggest good agreement between the spectral IR and VNIR IOT retrievals. However, as illustrated in the following section, for the MODIS C5 retrievals (solid lines) the modes of the distributions vary with scan angle, and the bias is seen to be increasing as a function of scan angle. The dependence on the scan angle (i.e. scattering angle) for the $\mathrm{C} 5$ retrievals results from the strong angular variation in the $\mathrm{C} 5$ phase functions. This is an important result, as it demonstrates necessity that this scattering angle dependence can provide an additional constraint on ice radiative model selection. In addition, because CALIPSO and Aqua have similar orbits, only a small range of MODIS viewing angles are included in the collocated intercomparison; thus, the possible strong dependence on viewing angle implies the collocated analysis is representative only of the view angle ranges sampled. Finally, given the lack of significant scattering in the IR, the scan-dependent bias further suggests the issue is with the MODIS C5 VNIR retrievals. This is investigated in the next section.

\section{Investigating the sensitivity of ice scattering model selections for MODIS and CALIOP ice cloud retrievals}

\subsection{Ice radiative model sensitivities in MODIS}

Though a primary focus of this investigation is on optimizing C6 ice models to improve IOT intercomparisons, it is understood that ice model crystal habits also affect the particle single-scattering albedo retrieved using the SWIR and MWIR channels that provide effective particle size information. Figure $5 \mathrm{a}$ and $\mathrm{b}$ show the 2.13 and $3.7 \mu \mathrm{m}$ channel coalbedo, respectively, as a function of cloud effective radius (CER) for four habit realizations, namely the C5 habit mixture (black line) and the three severely roughened habits, i.e., solid aggregate plates (green line), solid bullet rosettes (red line), and aggregate columns (blue line) (Yang et al., 2012). To the extent that CER retrievals of an asymptotically thick cloud in the SWIR/MWIR are essentially a retrieval of coalbedo, the difference between the aggregated column and C5 model co-albedo implies an effective radius difference of +2 and $-8 \mu \mathrm{m}$ at the 2.1 and $3.7 \mu \mathrm{m}$ wavelengths, respectively, for a C5 effective radius of about $35 \mu \mathrm{m}$; smaller C5 retrieved sizes would result in larger differences.

Figure 6 shows the asymmetry parameter sensitivity to habit for the same four habits shown in Fig. 5. Evidently the habit sensitivity of the asymmetry parameter is also strong in both the 2.1 and $3.7 \mu \mathrm{m}$ MODIS channels. While the asymmetry parameters of three severely roughened habits are not constant with effective size (though at $2.1 \mu \mathrm{m}$ the aggregate plates and aggregate columns are nearly constant), the C5 model has much larger size sensitivity at both wavelengths (Cole et al., 2014; van Diedenhoven et al., 2014; Yang et al., 2008). Aggregated columns, with smaller asymmetry parameters relative to $\mathrm{C} 5$, will result in a larger retrieved CER estimates. This is because the resulting increase in modeled SWIR reflectance for a given effective size causes the measured reflectance to be associated with a more absorbing (i.e., larger) particle. Therefore, the effect of both co-albedo and 

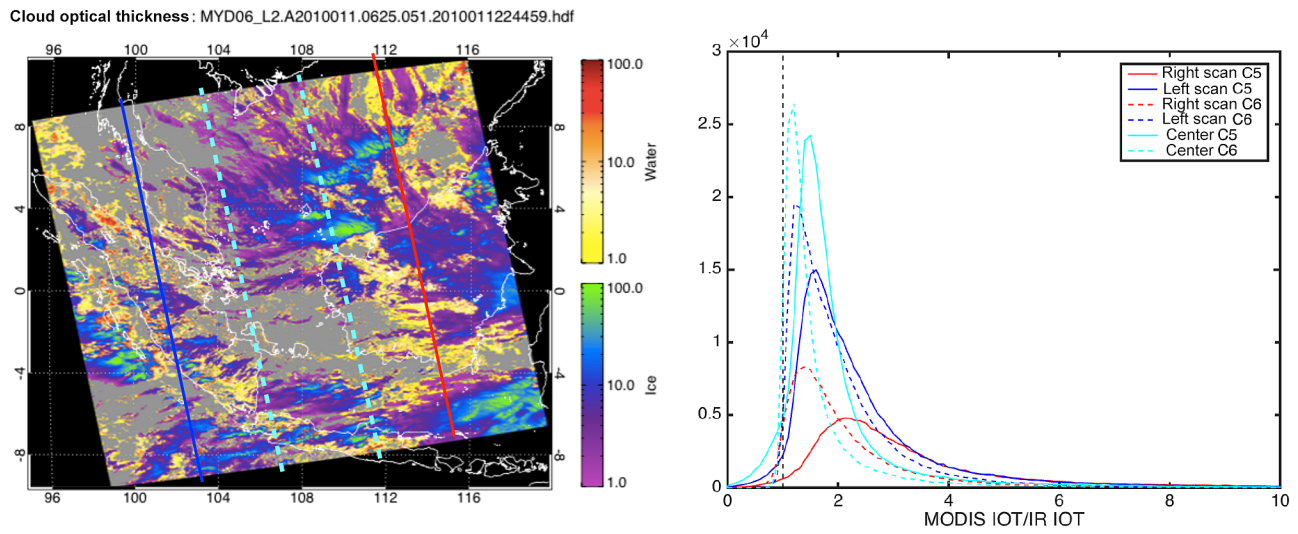

Figure 4. The MODIS IOT retrievals dependence on scan angle is investigated in the above panels. The image presents the MODIS C5 IOT retrievals on 11 January 2010 at 06:25 UTC. The right panel presents a histogram of the ratio between the MODIS IOT for both C5 (solid line) and C6 (dashed line) and full-swath IR retrieval for only those FOVs which were identified as ice by MODIS. The histograms are separated by view angle the approximate regions for each color marked by the associated color lines on the left image. Note the significant scan-dependent bias relative to the IR IOT for the MODIS C5 retrievals.
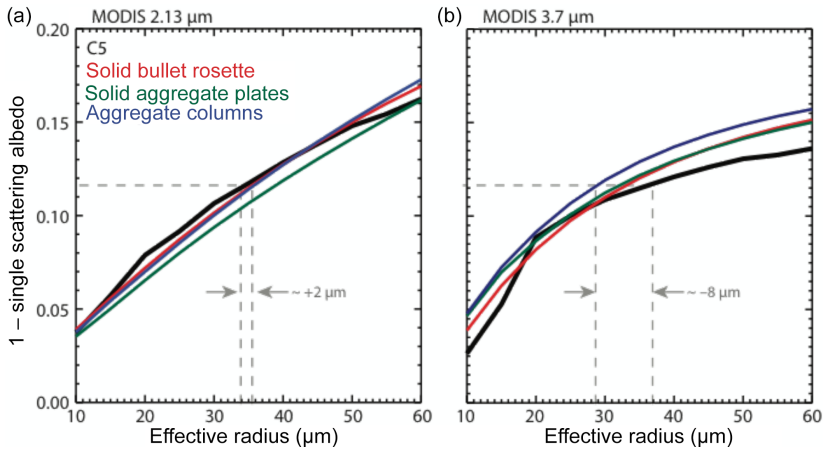

Figure 5. The relationship between effective radius and singlescattering co-albedo in the MODIS (a) 2.13 and (b) $3.7 \mu \mathrm{m}$ channels for different ice particle radiative models. See Fig. 6 for model details. Since effective radius retrievals for an optically thick cloud are a retrieval of co-albedo, the difference between the $\mathrm{C} 5$ and aggregated column model co-albedo implies a retrieved effective radius difference of +2 and $-8 \mu \mathrm{m}$, respectively, for a $\mathrm{C} 5$ effective radius retrieval of about $35 \mu \mathrm{m}$.

asymmetry parameter differences between the severely aggregated column habit and the $\mathrm{C} 5$ model act to increase retrieved effective radii at $2.1 \mu \mathrm{m}$, while at $3.7 \mu \mathrm{m}$ some cancellation of effects can be expected.

The single-habit radiative models shown in Figs. 5 and 6 are used to build lookup tables that were integrated into the MODIS C6 cloud retrieval development code. A month of data was processed for each habit. It was found that the habit that provided the best consistency with the IR window retrievals (Sect. 2.1.1) is the severely roughened aggregated column model. The IOT retrieval comparison with the IR window retrievals using this model is shown in Fig. 7a, where the MODIS reflectance-based retrievals using the severely roughened aggregated column model are now
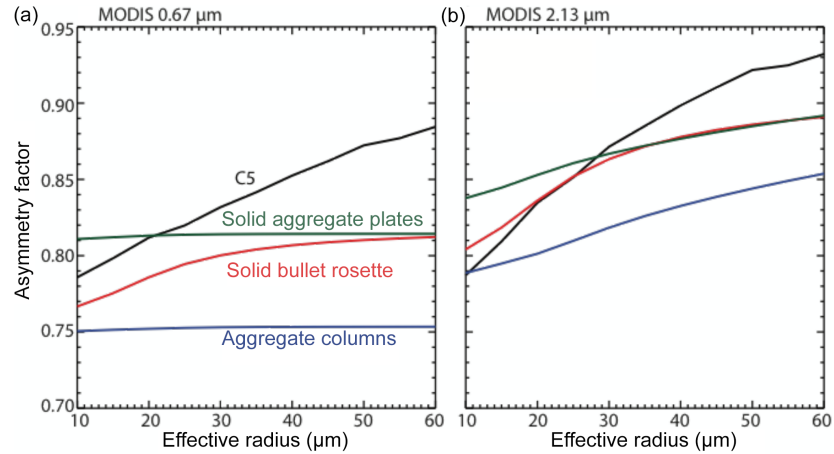

Figure 6. The relationship between effective radius and singlescatter asymmetry parameter in the MODIS (a) 0.67 and (b) $2.13 \mu \mathrm{m}$ channels for different ice particle radiative models. Note the strong dependence of the MODIS C5 model asymmetry parameter on effective size. The other models consist of a single habit with severely roughened surfaces. The single-habit calculations are made for a modified gamma size distribution and an effective variance of 0.10 .

clustered around the 1-to-1 line. In addition, this aggregated column model was used to assess the MODIS retrieval swath dependence previously shown in Fig. 4b. The improvement of the aggregated column model (dashed lines) relative to the C5 model (solid lines) is significant. Both results led to the decision to use the severely roughened aggregated column radiative model for the MODIS C6 cloud optical/microphysical property retrievals.

Figure 8 shows an example of ice cloud retrievals for C5 and C6 for typhoon Fung-Wong. The typhoon was located south of Taiwan at the time of the MODIS Aqua data granule acquisition on 20 September 2014 (05:30 UTC). The C5 and C6 ice (cool colors) and liquid (warm colors) cloud optical thickness retrievals are shown in the middle and right 

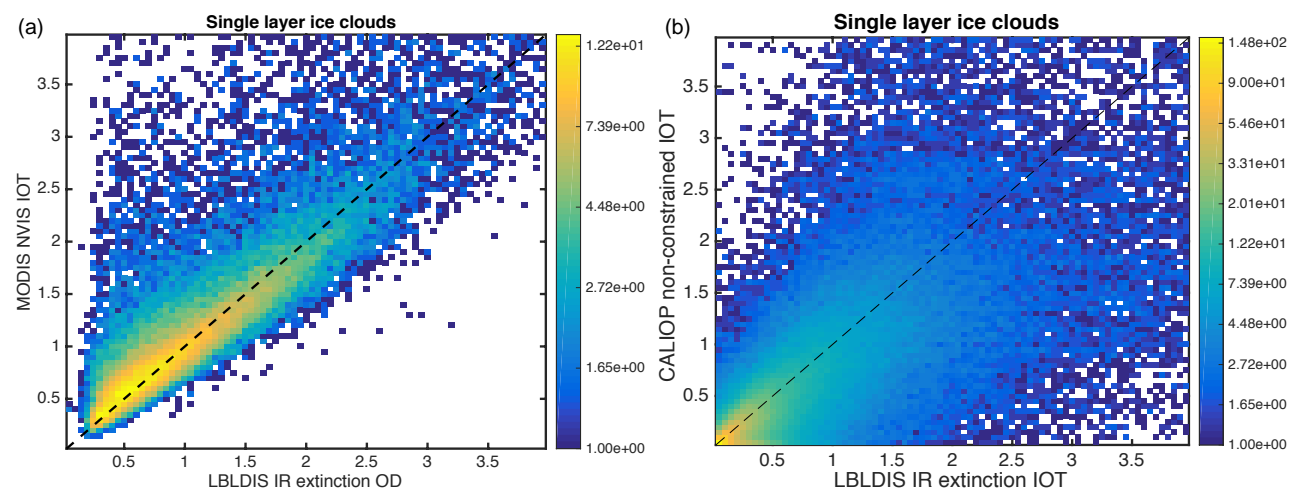

Figure 7. The joint histogram comparing the MODIS C6 IOT with the reference IOT retrieval (a). Note the significant improvement in the agreement resulting from the change to severely roughened aggregated columns. The CALIOP non-constrained IOT using a modified lidar ratio of 32 is compared to collocated IR MODIS retrieved IOT in panel (b). Note the significant improvement in the non-linear bias compared to Fig. 3b.

panels, respectively. In addition to ice radiative model differences, MYD06 C5 and C6 have different schemes for the cloud thermodynamic phase yielding different ice and liquid phase pixel populations, though the optical thickness spatial patterns are similar for regions having the same phase. Because of the different phase assignments made by these two scheme, quantifying ice model retrieval sensitivities requires that the comparisons be restricted to only those pixels for which both algorithms generate successful retrievals that identify identical cloud phases. With this pixel filtering, the left panel of Fig. 8b shows the normalized IOT distribution for the optical thickness range of the plot. The C6 IOT mode is roughly $27 \%$ smaller than the C5 mode, while the mean is decreased by about $15 \%$, from 4.16 for C5 to 3.55 for C6. The $2.1 \mu \mathrm{m}$ ice cloud effective particle radius retrievals are shown in the right panel, with the $\mathrm{C} 6$ mode and mean both increasing by about $4 \mu \mathrm{m}(+15 \%)$ for C6 relative to C5.

\subsection{MODIS C6 model selection methodology}

The MODIS IOT retrieval depends strongly on assumed ice scattering properties that are needed to relate the measured reflectance to the retrieved IOT. The MODIS C5 retrieval used empirically derived habit and size distributions with asymmetry parameters ranging between 0.79 and 0.88 depending on the ice cloud effective radius (Baum et al., 2005). By conducting an infrared closure analysis, we have shown that the C5 parameterization is not representative of the globally averaged ice scattering properties. More recent investigations of the ice cloud asymmetry parameter suggest that most ice clouds have values around 0.75 in the visible spectrum (Cole et al., 2012; van Diedenhoven et al., 2013). Additionally, use of the $\mathrm{C} 5$ ice cloud radiative model results in MODIS retrieval biases that are strongly dependent on the viewing angle, as demonstrated in Fig. 4. These findings motivated the investigation of new ice scattering models that have lower asymmetry parameters and weaker dependence on ice effective radius.

Since the MODIS C5 algorithms were finalized, new ice scattering models that incorporate roughened ice crystal parameterizations have been developed (Yang et al., 2012). Experimentation with these new models demonstrates that a modified gamma distribution of severely roughened aggregated columns provides a significantly lower visible asymmetry parameter $(\sim 0.75)$ that shows very little dependence on ice effective radius. For testing purposes, the MODIS cloud retrieval algorithm team implemented these new scattering properties in the MYD06 retrieval algorithm. The updated algorithm was then run on the Atmospheric PEATE and the resulting data were collocated with CALIOP measurements. Simulated TOA cloudy MODIS $11 \mu \mathrm{m}$ BTs were then computed using the reprocessed MODIS IOT retrievals and are compared to the MODIS measured BT. These new results are presented in Fig. 10b. The updated ice scattering models generate greatly improved IOT estimates that show very close to a one-to-one correspondence with the independently derived IR IOT values (Fig. 7a) and is consistent with the findings of Baum et al. (2014). Additionally the view-angle-dependent bias is largely removed, as presented in Fig. 4b. Based on these results, the recently reprocessed MODIS C6 cloud optical/microphysical property product (now in forward production) uses a modified gamma distribution consisting of a single habit of severely roughened aggregated columns for ice cloud retrievals. An additional benefit of the single habit is that it simplifies the retrieval and increases the reproducibility of the scattering properties by the research community. It is important to note that the selection of the single-habit modified gamma distribution was to provide a radiative consistency with the IR, not a microphysical model.

Figure 10a presents the same filtered 2-D histogram comparing CALIOP and MODIS as Fig. 1 but using the ice ra- 
(a)

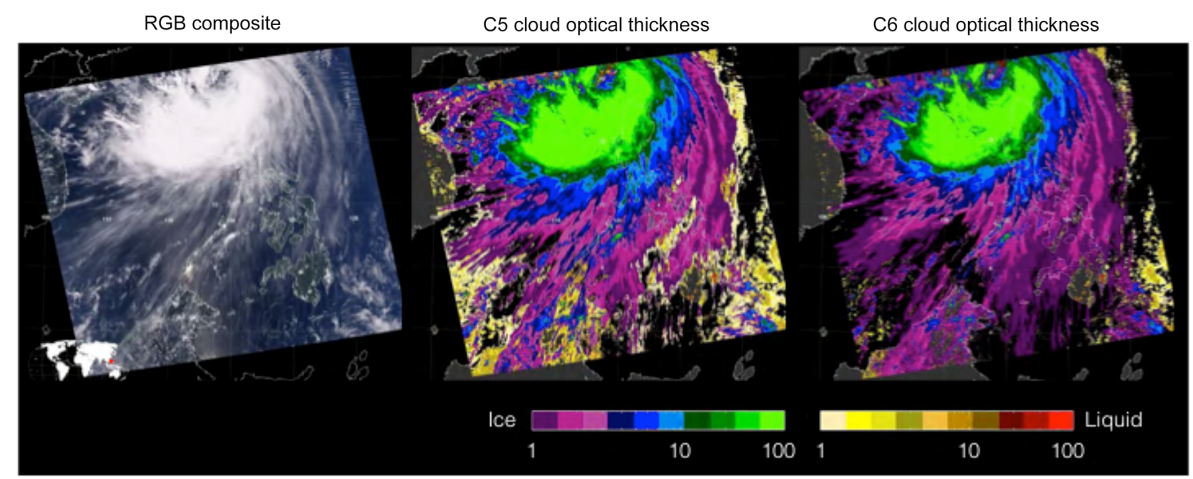

(b)

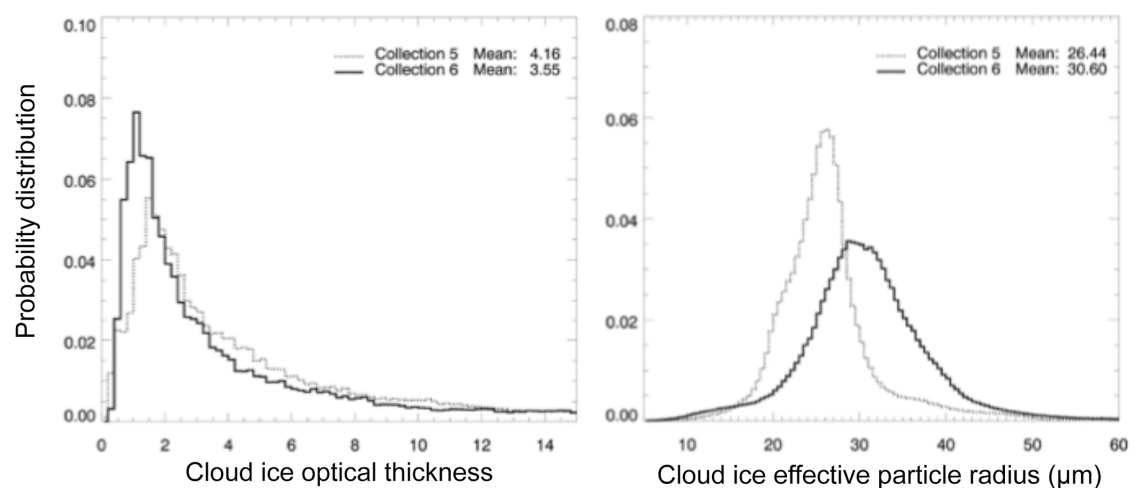

Figure 8. (a) Example retrieval results for an Aqua MODIS data granule (MYD06 2014, 20 September, 05:30 UTC). The RGB composite is shown in the left panel, while IOT retrievals for collections 5 and 6 are shown in the center and right panels, respectively. Note the difference in the phase determination between the two collections. (b) Collection 5 and 6 distributions of ice cloud optical thickness and effective radius derived from a combination of the MODIS 0.86 and $2.1 \mu \mathrm{m}$ channels for the data granule of (a). The distributions are limited to common pixels for which both collections agree that the pixel has an ice phase and the retrievals were successful. The IOT modes are at about 1.5 and 1.1 for $\mathrm{C} 5$ and $\mathrm{C} 6$, respectively, representing about a $27 \%$ reduction in the most recent collection; the effective radius modes increase by about $15 \%$. The mean for the range shown in the plots is given in the legends.

diative model modifications made for MODIS and the updated lidar ratio $(32 \mathrm{sr}$ ) for CALIOP. Figure $10 \mathrm{~b}$ presents the IR radiative closure for the updated IOT retrievals for January 2010. Note that the large bias between the MODIS and CALIOP un-constrained IOT is significantly reduced and the IR radiative closure shows very good agreement for all three IOT retrievals. There is still a tendency for the MODIS IOT to be larger than CALIOP in Fig. 10a. The MODIS C6 IR closure in Fig. 10b also demonstrates this bias, with the tail of the distribution weighted to negative BT differences, suggesting the remaining bias is specific to MODIS.

\subsection{Ice lidar ratio sensitivities in CALIOP}

As previously discussed, CALIOP uses one of two methods (i.e., constrained and unconstrained) to retrieve IOT. The constrained method requires high SNR in clear-air regions immediately above and below the cloud. This SNR requirement limits the constrained retrieval primarily to nighttime
FOVs, because solar background light severely degrades the clear-air SNR during the daytime. This precludes direct comparison of the constrained retrievals with the MODIS daytime optical property retrievals. The IR retrieval, being day/night independent, allows for direct intercomparisons between the MODIS IR IOT retrievals and both the constrained and un-constrained CALIOP IOT retrievals, providing a means to evaluate the two retrieval methods against a consistent reference.

Figure $3 \mathrm{~b}$ presents the joint histogram between the unconstrained CALIOP and the MODIS window IR IOT for January 2010 for single-layer cirrus. The filtering criteria are the same as in Fig. 1, except both day and night observations are included. The CALIOP layer optical thickness is filtered using the extinction quality control (QC) flags provided as part of the L2 products. Only QC values of 0 (unconstrained solution, no lidar ratio adjustment), 2 (unconstrained solution, lidar ratio decreased), and 4 (unconstrained solution, lidar ra- 


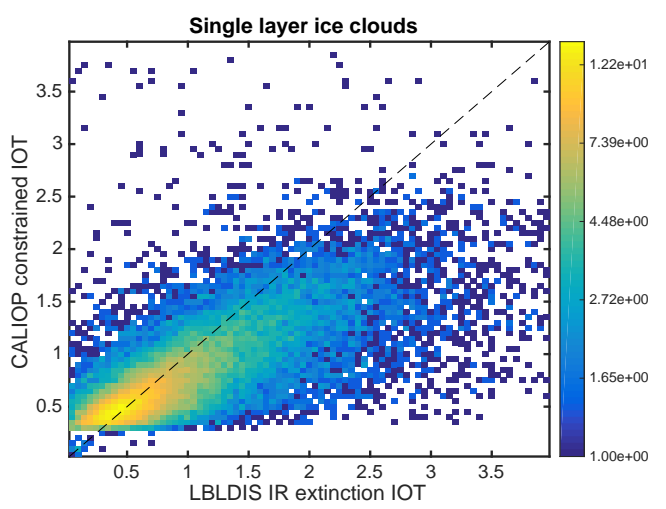

Figure 9. The CALIOP V3 constrained IOT retrieval for singlelayer clouds is compared to the LBLDIS reference IOT retrieval. Due to signal-to-noise limitations the comparison is limited to nighttime-only FOV.

tio increased) were selected. Consistent with the findings of Garnier et al. (2015a), Fig. 3b shows CALIOP unconstrained IOT is significantly low-biased with respect to the IR IOT, with a nonlinear dependence as a function of IOT. Figure 9 compares the CALIOP constrained retrievals $(\mathrm{QC}=1)$ to the MODIS IR COT for the same filtering criteria. This comparison reveals a distinct difference between the CALIOP constrained and unconstrained retrievals (Fig. 3b), as the constrained retrievals demonstrate a significantly smaller bias relative to the IR IOT. While the CALIOP IOT retrieval requires estimates of the multiple-scattering contributions for both the constrained and unconstrained retrievals, the unconstrained method also requires an assumed lidar ratio, whereas the constrained retrieval does not. Because both retrievals use identical fixed multiple-scattering factors, the difference between the constrained and unconstrained retrievals relative to the IR can be attributed to the use of an assumed lidar ratio in the unconstrained retrieval.

To investigate the sensitivity of the CALIOP IOT retrievals to the lidar ratio, a month of CALIOP L2 products was processed (January 2010) with the default lidar ratio increased to $32 \mathrm{sr}$. This revised value is the mean of all V3 constrained solutions of ice clouds with randomly oriented ice crystals (3 091952 cases) measured between 28 November 2007 (when CALIPSO permanently changed its pointing angle to $3^{\circ}$ off nadir) and 30 June 2012. It is important to note that the selection of this new default lidar ratio was based on on-going quality assurance analyses conducted by the CALIOP algorithm team that were wholly independent of the IR intercomparisons with the final value dependent on change to the multiple-scattering correction and calibration. In addition, the CALIOP team is currently investigating a more complex multiple-scattering parameterization that depends on the cloud temperature (Garnier et al., 2015b). The modified CALIOP product was ingested by the Atmospheric PEATE and collocated with both the MODIS C5 and C6 products and the MODIS IR retrievals. The modified CALIOP unconstrained retrievals compared to the reference IR IOT is presented in Fig. 7b. Compared to the standard V3 products (Fig. $3 b$ ) the change in the lidar ratio significantly reduced the bias compared to IR IOT, and the nonlinear behavior at large IOT is almost completely removed. This is because optical depth is a nonlinear function of lidar ratio; thus, weakly scattering layers show minimal changes in IOT, while the changes in strongly scattering layers are much more substantial. This result strongly suggests that the current V3 unconstrained lidar ratio of $25 \mathrm{sr}$ should be increased in future versions of the CALIOP data products.

\section{Conclusions}

MODIS Collection 5 (C5) ice optical thickness (IOT) retrievals are compared to the CALIOP Version 3 (V3) IOT for 1 month (January 2010) of collocated single-layer ice clouds. The comparison reveals a factor of 2 differences between the retrievals as presented in Fig. 1. Using IR observations from MODIS as an independent means of assessing the CALIOP and MODIS IOT clearly demonstrates that both retrievals have significant biases, but in opposite directions: MODIS C5 systematically overestimates IOT, while CALIOP V3 systematically underestimates IOT.

The decision to use the single severely roughened aggregate column habit as the MODIS C6 ice cloud radiative model was made solely to achieve closure with IR retrievals in a global sense. Our use of this model for this purpose does not imply that it is a suitable microphysical model for use in understanding ice particle physical processes (e.g., size distribution evolution, fall speed distribution). Furthermore, the IR comparisons were done in conjunction with collocated CALIOP observations that allow for the filtering of multilayer ice-phase clouds from the statistical study; the data set used here is clearly a subset of actual scenes and so may not be reflective of the full distribution of ice clouds observed by the sensors. It is important to note that this investigation focuses on ice clouds with optical depths less then 3.0 as this is the limit for CALIOP. Finally, it is recognized that using a fixed ice radiative model for global retrievals is only meaningful in a climatological sense and may be expected to breakdown in instantaneous and/or regional studies with variations in inferred ice models with region, cloud type, dynamics, and cloud-top height shown by Cole et al. (2014) and van Diedenhoven et al. (2014).

The severely roughened aggregated column model adopted for the MODIS C6 ice cloud algorithm has a fixed aspect ratio with an asymmetry parameter of about 0.75 in the visible for all effective sizes. This produces results that are quite consistent with those generated using the Inhomogeneous Hexagonal Monocrystal (IHM) model derived by C.-Labonnote et al. (2001) (asymmetry parameter of about 0.77) that provided a good match with observed POLDER 

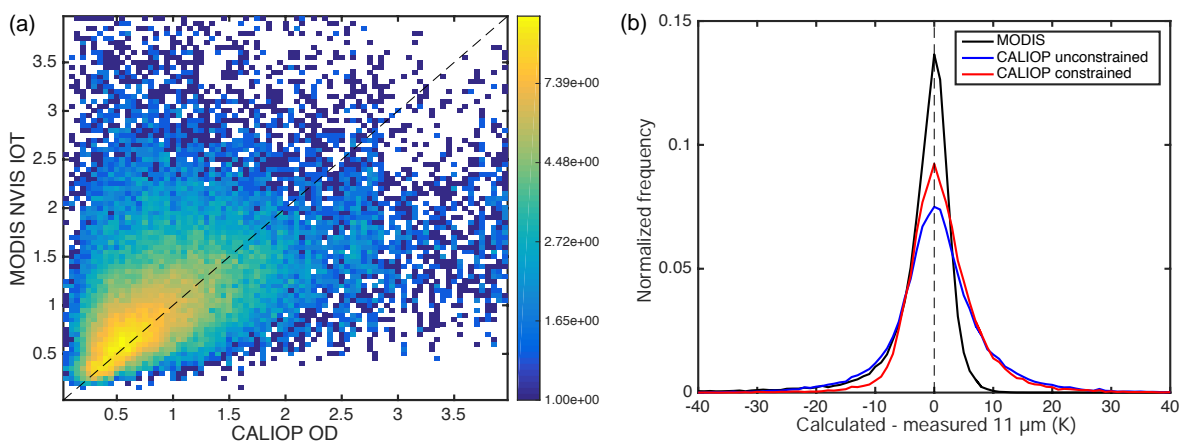

Figure 10. The CALIOP unconstrained IOT but processed using a modified lidar ratio of 32 is compared to the new single-habit ice scattering lookup table used in the updated MODIS C6 IOT retrievals in (a). Note the improved bias relative to the MODIS C5 and V3 CALIOP retrievals presented in Fig. 1. The radiative closure analysis using the updated retrievals is presented in (b). The modifications have greatly improved agreement with the measured MODIS $11 \mu \mathrm{m}$ channel compared to MODIS C5 and the current V3 CALIOP retrievals presented in Fig. 2.

view-angle-dependent VNIR reflectance. Other studies have also suggested that featureless (i.e., smooth) phase functions indicative of roughened or highly asymmetric aggregated habits with relatively small asymmetry parameters are needed to match aircraft and satellite observations (e.g., Baran et al., 2001; C.-Labonnote et al., 2000; van Diedenhoven et al., 2013).

The Generalized Habit Model (GHM) (Baum et al., 2010) was also tested but did not result in the same level of radiative closure with the IR IOT retrievals compared to the severely roughened aggregated columns (comparison shown in Fig. 7a). While there was an improvement with respect to the C5 ice model (comparison shown in Fig. 3a), the GHM model resulted in IOT retrievals that were still significantly larger than the IR because of larger asymmetry parameters in the visible relative to the severely roughened aggregated column model (about 0.77 at an effective radius of $5 \mu \mathrm{m}$ up to 0.82 at $60 \mu \mathrm{m}$ ). Cole et al. (2012) also tested the GHM as well as single-habit models from Yang et al. $(2012,2003)$ against POLDER polarized and total reflectance observations across a range of scattering angles.

Polarized angular observations agreed well with a severely roughened version of the GHM. However, it was concluded that there was no single habit/model that is best in all respects for the reflectance (derived spherical albedo) consistency tests, though the severely roughened aggregated column model was not included in the analysis. Similarly, Baran and Labonnote (2007) also noted that though the IHM model provided good consistency with POLDER directional reflectance distributions, it was less successful in matching the angular distribution of polarized reflectances. Due to vertical size stratification in ice clouds it is possible that different models are needed to match polarized observations (weighted towards the uppermost portion of the cloud top) with total reflectance observations (weighted deeper into the cloud) (e.g., Platnick, 2000; Zhang et al., 2010).
Given that MODIS retrievals are based on total reflectance, it is expected that directional reflectance consistency with POLDER is the more relevant metric. Further, the study of Zhang et al. $(2010,2009)$ shows there is little difference between IOT retrieved from reflectance and IR observations for the model case study considered. Fauchez et al. (2014) demonstrated that, for $1 \mathrm{~km}$ IR observations, sensitivities to 3-D effects are limited to horizontal heterogeneity (planeparallel approximation (PPA) bias) and the effect of vertical heterogeneity is small. Though more extensive heterogeneity studies are needed, these studies do suggest the utility of using IR IOT retrievals to assess MODIS reflectance-based ice radiative models. Finally, we note that recent comparisons have demonstrated consistency between Aqua MODIS C6 IOT retrievals and those from AIRS Version 6 (Kahn, 2015).

For CALIOP it is found that the bias relative to the IR for the V3 IOT retrievals depends on the retrieval method used. While CALIOP can make direct measurements of the effective two-way transmittance of the layer, the retrieved optical thickness depends only on an estimate of the multiplescattering factor and the accuracy of the molecular attenuated backscatter profile (calculated from a temperature and pressure profile using Rayleigh scattering theory). However, daytime solar background noise limits the applicability of this constrained retrieval technique to mostly nighttime observations, thus prohibiting direct comparisons to the MODIS daytime optical retrievals. For the constrained retrieval we find good agreement with the IR radiative closure (Fig. 2) and the IR IOT in Fig. 9. However, the majority of the daytime CALIOP retrievals use the unconstrained method that requires an a priori specification of the cloud extinction-tobackscatter ratio. It is these unconstrained retrievals that are directly compared to the MODIS C5 IOT in Fig. 1 and to the IR in Figs. 2 and 3. The CALIOP V3 unconstrained IOT retrievals show a significant low bias relative to both the IR and the constrained CALIOP retrievals. Since both CALIOP methods assume an identical multiple-scattering correction, 
this suggests that the default lidar ratio $(25 \mathrm{sr})$ used in the V3 CALIOP unconstrained retrievals is too low. As part of this investigation the CALIOP algorithm team processed a month of retrievals using a lidar ratio of $32 \mathrm{sr}$ for the unconstrained retrievals with results presented in Fig. 7b. It is important to note that the selection of a lidar ratio of $32 \mathrm{sr}$ was not based on the IR intercomparison studies but was instead derived from independent analyses of the nighttime constrained retrievals conducted by the CALIOP algorithm team in order to improve the accuracy of the CALIOP unconstrained retrievals and increase the consistency of IOTs reported by the constrained and unconstrained retrievals.

\section{Data availability}

$\begin{array}{lrrrrr}\text { All } & \text { relevant data can be } & \text { accessed } & \text { from } \\ \text { the } & \text { NASA } & \text { data } & \text { centers } & \text { using } & \text { these }\end{array}$ DOIs: doi:10.5067/MODIS/MOD06_L2.006, doi:10.5067/CALIOP/CALIPSO/CAL_LID_L2_05kmCProProv-V3-01_L2-003.01, and doi:10.5067/CALIOP/CALIPSO/CAL_LID_L2_05kmCLayProv-V3-01_L2-003.01.

Acknowledgements. We would like to acknowledge the NASA University of Wisconsin Atmospheric PEATE/SIPS, which provided the processing and data accessed needed to conduct this research. We would also like to thank the CALIOP and MODIS algorithm teams for their support. This research was funded by NASA grant NNX15AG12G and NASA Langley Contract SSAI Task A-014 E-001D.

Edited by: B. Mayer

\section{References}

Ackerman, S. A., Strabala, K. I., Menzel, W. P., Frey, R. A., Moeller, C. C., and Gumley, L. E.: Discriminating clear sky from clouds with MODIS, J. Geophys. Res., 103, 32141-32157, doi:10.1029/1998JD200032, 1998.

Ackerman, S. A., Holz, R. E., Frey, R., Eloranta, E. W., Maddux, B., and McGill, M. J.: Cloud detection with MODIS: Part II Validation, J. Atmos. Ocean. Tech., 25, 1073-1086, 2008.

Baran, A. J. and Labonnote, L. C.: A self-consistent scattering model for cirrus. I: The solar region, Q. J. Roy. Meteor. Soc., 133, 1899-1912, 2007.

Baran, A. J., Francis, P. N., Labonnote, L. C., and DoutriauxBoucher, M.: A scattering phase function for ice cloud: Tests of applicability using aircraft and satellite multi-angle multiwavelength radiance measurements of cirrus, Q. J. Roy. Meteor. Soc., 127, 2395-2416, 2001.

Baum, B. A., Yang, P., Heymsfield, A. J., Platnick, S., King, M. D., Hu, Y.-X., and Bedka, S. T.: Bulk Scattering Properties for the Remote Sensing of Ice Clouds. Part II: Narrowband Models, J. Appl. Meteorol., 44, 1896-1911, 2005.

Baum, B. A., Yang, P., Heymsfield, A. J., Schmitt, C. G., Xie, Y., Bansemer, A., Hu, Y.-X., and Zhang, Z.: Improvements in Short- wave Bulk Scattering and Absorption Models for the Remote Sensing of Ice Clouds, J. Appl. Meteorol. Clim., 50, 1037-1056, 2010.

Baum, B. A., Yang, P., Heymsfield, A. J., Bansemer, A., Cole, B. H., Merrelli, A., Schmitt, C., and Wang, C.: Ice cloud singlescattering property models with the full phase matrix at wavelengths from 0.2 to $100 \mu \mathrm{m}$, J. Quant. Spectrosc. Ra., 146, 123 139, 2014.

C.-Labonnote, L., Brogniez, G., Doutriaux-Boucher, M., Buriez, J.C., Gayet, J.-F., and Chepfer, H.: Modeling of light scattering in cirrus clouds with inhomogeneous hexagonal monocrystals. Comparison with in-situ and ADEOS-POLDER measurements, Geophys. Res. Lett., 27, 113-116, 2000.

C.-Labonnote, L., Brogniez, G., Buriez, J.-C., Doutriaux-Boucher, M., Gayet, J.-F., and Macke, A.: Polarized light scattering by inhomogeneous hexagonal monocrystals: Validation with ADEOS-POLDER measurements, J. Geophys. Res.-Atmos., 106, 12139-12153, 2001.

Clough, S. A. and Moncet, J. L.: Line by line calculations of atmosheric fluxes and cooling rates: Application to carbon dioxide, ozone, methane, nitrous oxide, an the halocarbons, J. Geophys. Res., 97, 761-785, 1992.

Cole, B. H., Yang, P., Baum, B. A., Riedi, J., and C.-Labonnote, L.: Ice particle habit and surface roughness derived from PARASOL polarization measurements, Atmos. Chem. Phys., 14, 37393750, doi:10.5194/acp-14-3739-2014, 2014.

Cole, B. H., Yang, P., Baum, B. A., Riedi, J., C.-Labonnote, L., Thieuleux, F., and Platnick, S.: Comparison of PARASOL Observations with Polarized Reflectances Simulated Using Different Ice Habit Mixtures, J. Appl. Meteorol. Clim., 52, 186-196, 2012.

Corti, T. and Peter, T.: A simple model for cloud radiative forcing, Atmos. Chem. Phys., 9, 5751-5758, doi:10.5194/acp-9-57512009, 2009.

Delanoë, J. and Hogan, R. J.: Combined CloudSat-CALIPSOMODIS retrievals of the properties of ice clouds, J. Geophys. Res.-Atmos., 115, 2156-2202, 2010.

Fauchez, T., Cornet, C., Szczap, F., Dubuisson, P., and Rosambert, T.: Impact of cirrus clouds heterogeneities on top-of-atmosphere thermal infrared radiation, Atmos. Chem. Phys., 14, 5599-5615, doi:10.5194/acp-14-5599-2014, 2014.

Fu, Q., Carlin, B., and Mace, G.: Cirrus horizontal inhomogeneity and OLR bias, Geophys. Res. Lett., 27, 3341-3344, 2000.

Garnier, A., Pelon, J., Vaughan, M. A., Winker, D. M., Trepte, C. R., and Dubuisson, P.: Optical depths of semi-transparent cirrus clouds over oceans from CALIPSO infrared radiometer and lidar measurements, and an evaluation of the lidar multiple scattering factor, Atmos. Meas. Tech. Discuss, 8, 2143-2189, doi:10.5194/amtd-8-2143-2015, 2015a.

Garnier, A., Pelon, J., Vaughan, M. A., Winker, D. M., Trepte, C. R., and Dubuisson, P.: Lidar multiple scattering factors inferred from CALIPSO lidar and IIR retrievals of semi-transparent cirrus cloud optical depths over oceans, Atmos. Meas. Tech., 8, 27592774, doi:10.5194/amt-8-2759-2015, 2015b.

Heidinger, A., Li, Y., Baum, B., Holz, R., Platnick, S., and Yang, P.: Retrieval of Cirrus Cloud Optical Depth under Day and Night Conditions from MODIS Collection 6 Cloud Property Data, Remote Sensing, 7, 7257-7271, 2015. 
Heidinger, A. K., Foster, M. J., Walther, A., and Zhao, X.: The Pathfinder Atmospheres-Extended AVHRR Climate Dataset, B. Am. Meteorol. Soc., 95, 909-922, 2013.

Holz, R. E.: Measurement cirrus backscatter phase functions using a high spectral resolution lidar, Atmospheric and Oceanic Sciences, University of Wisconsin-Madison, 67 pp., 2002.

Holz, R. E., Ackerman, S. A., Nagel, F. W., Frey, R., Dutcher, S., Kuehn, R. E., Vaughan, M. A., and Baum, B. A.: Global MODIS Cloud Detection and Height Evaluated Using CALIOP, J. Geophys. Res., 113, D00A19, doi:10.1029/2008JD009837, 2008.

Hu, Y., Winker, D., Vaughan, M., Lin, B., Omar, A., Trepte, C., Flittner, D., Yang, P., Nasiri, S. L., Baum, B., Holz, R., Sun, W., Liu, Z., Wang, Z., Young, S., Stamnes, K., Huang, J., and Kuehn, R.: CALIPSO/CALIOP Cloud Phase Discrimination Algorithm, J. Atmos. Ocean. Tech., 26, 2293-2309, 2009.

Hunt, W. H., Winker, D. M., Vaughan, M. A., Powell, K. A., Lucker, P. L., and Weimer, C.: CALIPSO Lidar Description and Performance Assessment, J. Atmos. Ocean. Tech., 26, 1214-1228, 2009.

Jiang, J. H., Su, H., Zhai, C., Perun, V. S., Del Genio, A., Nazarenko, L. S., Donner, L. J., Horowitz, L., Seman, C., Cole, J., Gettelman, A., Ringer, M. A., Rotstayn, L., Jeffrey, S., Wu, T., Brient, F., Dufresne, J.-L., Kawai, H., Koshiro, T., Watanabe, M., LÉcuyer, T. S., Volodin, E. M., Iversen, T., Drange, H., Mesquita, M. D. S., Read, W. G., Waters, J. W., Tian, B., Teixeira, J., and Stephens, G. L.: Evaluation of cloud and water vapor simulations in CMIP5 climate models using NASA "A-Train" satellite observations, J. Geophys. Res.-Atmos., 117, 2156-2202, 2012.

Jin, H. and Nasiri, S. L.: Evaluation of AIRS CloudThermodynamic-Phase Determination with CALIPSO, J. Appl. Meteorol. Clim., 53, 1012-1027, 2013.

Josset, D., Pelon, J., Garnier, A., Hu, Y., Vaughan, M., Zhai, P.-W., Kuehn, R., and Lucker, P.: Cirrus optical depth and lidar ratio retrieval from combined CALIPSO-CloudSat observations using ocean surface echo, J. Geophys. Res.-Atmos., 117, 2156-2202, 2012.

Kahn, B. H.: Pixel-scale assessment and uncertainty analysis of AIRS and MODIS ice cloud optical thickness and effective radius, J. Geophys. Res., 120, 11669-11689, doi:10.1002/2015JD023950, 2015.

Kahn, B. H., Irion, F. W., Dang, V. T., Manning, E. M., Nasiri, S. L., Naud, C. M., Blaisdell, J. M., Schreier, M. M., Yue, Q., Bowman, K. W., Fetzer, E. J., Hulley, G. C., Liou, K. N., Lubin, D., Ou, S. C., Susskind, J., Takano, Y., Tian, B., and Worden, J. R.: The Atmospheric Infrared Sounder version 6 cloud products, Atmos. Chem. Phys., 14, 399-426, doi:10.5194/acp-14-399-2014, 2014.

King, M. D., Menzel, W. P., Kaufman, Y. J., Tanre, D., Gao, B. C., Platnick, S., Ackerman, S. A., Remer, L. A., Pincus, R., and Hubanks, P. A.: Cloud and aerosol properties, precipitable water, and profiles of temperature and humidity from MODIS, IEEE T. Geosci. Remote Sens., 41, 442-458, 2003.

King, M. D., Platnick, S., Menzel, W. P., Ackerman, S. A., and Hubanks, P. A.: Spatial and Temporal Distribution of Clouds Observed by MODIS Onboard the Terra and Aqua Satellites, IEEE T. Geosci. Remote Sens., 51, 3826-3852, 2013.

Liu, Z., Vaughan, M., Winker, D., Kittaka, C., Getzewich, B., Kuehn, R., Omar, A., Powell, K., Trepte, C., and Hostetler, C.: The CALIPSO Lidar Cloud and Aerosol Discrimination: Version
2 Algorithm and Initial Assessment of Performance, J. Atmos. Ocean. Tech., 26, 1198-1213, 2009.

Maestri, T. and Holz, R. E.: Retrieval of Cloud Optical Properties From Multiple Infrared Hyperspectral Measurements: A Methodology Based on a Line-by-Line Multiple-Scattering Code, IEEE T. Geosci. Remote Sens., 47, 2413-2426, 2009.

Mlawer, E. J., Taubman, S. J., Brown, P. D., Iacono, M. J., and Clough, S. A.: Radiative transfer for inhomogeneous atmospheres: RRTM, a validated correlated-k model for the longwave, J. Geophys. Res., 102, 2156-2202, 1997.

Nagle, F. W. and Holz, R. E.: Computationally Efficient Methods of Collocating Satellite, Aircraft, and Ground Observations, J. Atmos. Ocean. Tech., 26, 1585-1595, 2009.

Nakajima, T. and King, M. D.: Determination of the Optical Thickness and Effective Particle Radius of Clouds from Reflected Solar Radiation Measurements. Part I: Theory, J. Atmos. Sci., 47, 1878-1893, 1990.

Parol, F., Buriez, J. C., Brogniez, G., and Fouquart, Y.: Information Content of AVHRR Channels 4 and 5 with Respect to the Effective Radius of Cirrus Cloud Particles, J. Appl. Meteorol., 30, 973-984, 1991.

Pincus, R., Platnick, S., Ackerman, S. A., Hemler, R. S., and Hofmann, R. J.: Reconciling Simulated and Observed Views of Clouds: MODIS, ISCCP, and the Limits of Instrument Simulators, J. Climate, 25, 4699-4720, 2012.

Platnick, S.: Vertical photon transport in cloud remote sensing problems, J. Geophys. Res.-Atmos., 105, 22919-22935, 2000.

Platnick, S.: MODIS Cloud Optical Properties: User Guide for the Collection 6 Level-2 MOD06/MYD06 Product and Associated Level-3 Datasets, 141 pp., NASA Goddard, Greenbelt, MD, USA, 2014.

Platnick, S. and Twomey, S.: Determining the Susceptibility of Cloud Albedo to Changes in Droplet Concentration with the Advanced Very High Resolution Radiometer, J. Appl. Meteorol., 33, 334-347, 1994.

Platnick, S., Li, J. Y., King, M. D., Gerber, H., and Hobbs, P. V.: A solar reflectance method for retrieving the optical thickness and droplet size of liquid water clouds over snow and ice surfaces, J. Geophys. Res.-Atmos., 106, 15185-15199, 2001.

Powell, K. A., Hostetler, C. A., Vaughan, M. A., Lee, K.-P., Trepte, C. R., Rogers, R. R., Winker, D. M., Liu, Z., Kuehn, R. E., Hunt, W. H., and Young, S. A.: CALIPSO Lidar Calibration Algorithms. Part I: Nighttime 532-nm Parallel Channel and 532-nm Perpendicular Channel, J. Atmos. Ocean. Tech., 26, 2015-2033, 2009.

Rossow, W. B.: Use of Operational Satellite Data for Study of Clouds and Radiation in Climate, Global Planet. Change, 90, 3339, 1991.

Rossow, W. B. and Schiffer, R. A.: Advances in understanding clouds from ISCCP, B. Am. Meteorol. Soc., 80, 2261-2287, 1999.

Sassen, K. C. and Comstock, J. M.: A Midlatitude Cirrus Cloud Climatology from the Facility for Atmospheric Remote Sensing. Part III: Radiative Properties, J. Atmos. Sci., 58, 2113-2127, 2001.

Stamnes, K., Tsay, S., Wiscombe, W. J., and Jayaweera, K.: Numerically stable algorithim for discrete-ordinate-method radiative transfer in multiple scattering and emitting layered media, Appl. Optics, 27, 2502-2509, 1988. 
Stephens, G. L., Vane, D. G., Boain, R. J., Mace, G. G., Sassen, K., Wang, Z. E., Illingworth, A. J., O’Connor, E. J., Rossow, W. B., Durden, S. L., Miller, S. D., Austin, R. T., Benedetti, A., Mitrescu, C., and Team, C. S.: The cloudsat mission and the atrain - A new dimension of space-based observations of clouds and precipitation, B. Am. Meteorol. Soc., 83, 1771-1790, 2002.

Tobin, D. C., Revercomb, H. E., Moeller, C. C., and Pagano, T. S.: Use of Atmospheric Infrared Sounder high-spectral resolution spectra to assess the calibration of Moderate resolution Imaging Spectroradiometer on EOS Aqua, J. Geophys. Res., 111, D09S05, doi:10.1029/2005JD006095, 2006.

Turner, D. D., Ackerman, S. A., Baum, B. A., Revercomb, H. E., and Yang, P.: Cloud Phase Determination Using Ground-Based AERI Observations at SHEBA, J. Appl. Meteorol., 42, 701-715, 2003.

Van de Hulst, H. C.: The spherical albedo of a planet covered with a homogeneous cloud layer, Astron. Astrophys., 35, 209-214, 1974.

van Diedenhoven, B., Cairns, B., Fridlind, A. M., Ackerman, A. S., and Garrett, T. J.: Remote sensing of ice crystal asymmetry parameter using multi-directional polarization measurements Part 2: Application to the Research Scanning Polarimeter, Atmos. Chem. Phys., 13, 3185-3203, doi:10.5194/acp-13-31852013, 2013.

van Diedenhoven, B., Fridlind, A. M., Cairns, B., and Ackerman, A. S.: Variation of ice crystal size, shape, and asymmetry parameter in tops of tropical deep convective clouds, J. Geophys. Res.-Atmos., 119, 2169-8996, 2014.

Vaughan, M. A., Winker, D., and Powell, K. A.: CALIOP Algorithm Theoretical Basis Document, Part 2: Feature Detection and Layer Properties Algorithms, 1-87, NASA Langley, Langley, VA, USA, 2005.

Vaughan, M. A., Powell, K. A., Winker, D. M., Hostetler, C. A., Kuehn, R. E., Hunt, W. H., Getzewich, B. J., Young, S. A., Liu, Z., and McGill, M. J.: Fully Automated Detection of Cloud and Aerosol Layers in the CALIPSO Lidar Measurements, J. Atmos. Ocean. Tech., 26, 2034-2050, 2009.

Wind, G., Platnick, S., King, M. D., Hubanks, P. A., Pavolonis, M. J., Heidinger, A. K., Yang, P., and Baum, B. A.: Multilayer Cloud Detection with the MODIS Near-Infrared Water Vapor Absorption Band, J. Appl. Meteorol. Clim., 49, 2315-2333, 2010.

Winker, D.: Accounting for multiple scattering in retrievals from space lidar, SPIE, 5059, 128-139, 2003.

Winker, D. M., Pelon, J., Coakley, J. A., Ackerman, S. A., Charlson, R. J., Colarco, P. R., Flamant, P., Fu, Q., Hoff, R. M., Kittaka, C., Kubar, T. L., Le Treut, H., McCormick, M. P., Mégie, G., Poole, L., Powell, K., Trepte, C., Vaughan, M. A., and Wielicki, B. A.: The CALIPSO Mission: A Global 3D View of Aerosols and Clouds, B. Am. Meteorol. Soc., 91, 1211-1229, 2010.

Wylie, D., Jackson, D. L., Menzel, W. P., and Bates, J. J.: Trends in Global Cloud Cover in Two Decades of HIRS Observations, J. Climate, 18, 3021-3031, 2005.
Yang, P., Hu, Y. X., Winker, D. M., Zhao, J., Hostetler, C. A., Poole, L., Baum, B. A., Mishchenko, M. I., and Reichardt, J.: Enhanced lidar backscattering by quasi-horizontally oriented ice crystal plates in cirrus clouds, J. Quant. Spectrosc. Ra., 79-80, 1139-1157, 2003.

Yang, P., Lei, Z., Hong, G., Nasiri, S. L., Baum, B. A., Huang, H. L., King, M. D., and Platnick, S.: Differences Between Collection 4 and 5 MODIS Ice Cloud Optical/Microphysical Products and Their Impact on Radiative Forcing Simulations, IEEE T. Geosci. Remote Sens., 45, 2886-2899, 2007.

Yang, P., Hong, G., Kattawar, G. W., Minnis, P., and Yongxiang, H.: Uncertainties Associated With the Surface Texture of Ice Particles in Satellite-Based Retrieval of Cirrus Clouds: Part II; Effect of Particle Surface Roughness on Retrieved Cloud Optical Thickness and Effective Particle Size, IEEE T. Geosci. Remote Sens., 46, 1948-1957, 2008.

Yang, P., Bi, L., Baum, B. A., Liou, K.-N., Kattawar, G. W., Mishchenko, M. I., and Cole, B.: Spectrally Consistent Scattering, Absorption, and Polarization Properties of Atmospheric Ice Crystals at Wavelengths from 0.2 to $100 \mu \mathrm{m}$, J. Atmos. Sci., 70, 330-347, 2012.

Yongxiang, H., Vaughan, M., Liu, Z., Powell, K., and Rodier, S.: Retrieving Optical Depths and Lidar Ratios for Transparent Layers Above Opaque Water Clouds From CALIPSO Lidar Measurements, IEEE T. Geosci. Remote Sens. Lett., 4, 523-526, 2007.

Yorks, J. E., Hlavka, D. L., Hart, W. D., and McGill, M. J.: Statistics of Cloud Optical Properties from Airborne Lidar Measurements, J. Atmos. Ocean. Tech., 28, 869-883, 2011.

Young, S. A.: Analysis of lidar backscatter profiles in optically thin clouds, Appl. Optics, 34, 7019-7031, 1995.

Young, S. A. and Vaughan, M. A.: The Retrieval of Profiles of Particulate Extinction from Cloud-Aerosol Lidar Infrared Pathfinder Satellite Observations (CALIPSO) Data: Algorithm Description, J. Atmos. Ocean. Tech., 26, 1105-1119, 2009.

Zhang, Z. and Platnick, S.: An assessment of differences between cloud effective particle radius retrievals for marine water clouds from three MODIS spectral bands, J. Geophys. Res.-Atmos., 116, D20215, doi:10.1029/2011JD016216, 2011.

Zhang, Z., Yang, P., Kattawar, G., Riedi, J., C.-Labonnote, L., Baum, B. A., Platnick, S., and Huang, H.-L.: Influence of ice particle model on satellite ice cloud retrieval: lessons learned from MODIS and POLDER cloud product comparison, Atmos. Chem. Phys., 9, 7115-7129, doi:10.5194/acp-9-7115-2009, 2009.

Zhang, Z., Platnick, S., Yang, P., Heidinger, A. K., and Comstock, J. M.: Effects of ice particle size vertical inhomogeneity on the passive remote sensing of ice clouds, J. Geophys. Res.-Atmos., 115, D17203, doi:10.1029/2010JD013835, 2010. 